\title{
Retrograde Intramedullary Nailing in Femoral Fractures
}

\author{
Abhishek Garg*, Aman Saini, Anand Gupta, Rahul Sharma and RK Mishra \\ Department of Orthopaedics, PGIMS Rohtak, Haryana, India
}

Submission: September 20, 2021; Published: October 05, 2021

*Corresponding author: Dr Abhishek Garg, Senior Resident, Department of Orthopaedics, PGIMS Rohtak, Haryana, India

\section{Abstract}

Background: In comparison to plating methods, closed intramedullary nails require less soft tissue dissection, hence preserving periosteal blood supply subsequently leading to better functional outcomes of the fractures. In this study we aimed to evaluate the functional outcome of retrograde nailing for the management of distal femoral fractures.

Material and Methods: The present retrospective study included 10 cases aged between 20-70 years, who were operated for distal femoral shaft fractures over last 3 years with distal femoral nailing and their functional outcomes were noted.

Results: The mean age was $41.75 \pm 12.52$. Mean operating time was $125 \pm 10.15$ minutes. Mean blood loss was $230 \pm 20.5$ ml. Mean time for fracture union was $16.15 \pm 1.35$ weeks. No deep infection was noted. One case of non-union was noted in this study. 1 patient had anterior knee pain. Range of motion at knee at final follow up was $125.25 \pm 17.34$ degrees.

Conclusion: Retrograde distal femoral nailing provides a good method of fixation of distal femoral fractures allowing early mobilisation and better functional outcomes.

Keywords: Femur fracture, Retrograde nailing, intramedullary, knee pain, joint lavage

\section{Introduction}

Distal femur fractures have posed to be challenging for the surgeons throughout the course of their treatment [1]. The principles of treatment are to achieve anatomical reduction and preservation of the distal femoral blood supply with stable internal fixation with good functional outcomes. Blade plate or dynamic condylar screw are the traditionally used implants for the distal femoral fracture fixation [2]. Retrograde intramedullary nailing was developed with aim to avoid some of the complications associated with distal femoral fractures. The Distal Femoral Nail (DFN) is a retrograde femur nailing system, which is inserted through knee, locked in the proximally with screws and distally with either a twisted blade and one screw or with two screws [3,4]. This Distal femoral nailing was developed as an alternative to open reduction and internal fixation with plates. In comparison to plating methods, closed intramedullary nails require less soft tissue dissection, hence preserving periosteal blood flow subsequently leading to better functional outcomes of the fractures. Femoral nailing is also associated with excellent fracture healing and rapid recovery from surgery [5]. In this study we aimed to evaluate the functional outcome of retrograde nailing for the management of distal femoral fractures.

\section{Material and Methods}

The present retrospective study was conducted in the Department of Orthopaedics, PGIMS Rohtak and included 10 cases aged between 20-70 years, who were operated for distal femoral shaft fractures over last 3 years with distal femoral nailing. Patients were retrospectively followed up with all their previous surgical records and radiographs. Patients were clinically examined, and functional outcomes were noted. Patients with age more than 70 years, having congenital or acquired deformity of injured limb before surgery, pathological fractures and open fractures were excluded from the study. Radiographs were taken in two planes, anteroposterior view, and lateral view before planning for surgical fixation for distal femur fractures. Patients were laid supine with affected knee placed in $\sim 30^{\circ}$ flexion over operating table with a bolster underneath the knee. Knee flexion prevents distal fragment from being pulled into more flexion by gastrocnemius. Inferior pole of patella and borders of patella tendon were marked. A $2 \mathrm{~cm}$ incision was made from inferior pole of patella distal through tendon. We used a Transtendinous approach. Tenotomy was done to develop paratenon layer, sharp 


\section{Orthopedics and Rheumatology Open Access Journal (OROAJ)}

dissection through paratenon and then patellar tendon was done. Guide pin start point was in centre of intercondylar notch on anteroposterior view and just superior to Blumensaat's line on lateral view (Figure 1).

Guide pin position was checked on C-arm image to ensure pin was in centre of medullary canal. Fracture was reduced and sequential reaming was done. Nail was inserted over guidewire and was locked distally and proximally (Figure 2). After the nail insertion, thorough knee joint lavage to remove any reaming debris was done and the surgical incision was closed. Postoperatively vitals were monitored, intravenous antibiotics and analgesics were given. Radiographs were taken to ascertain implant position and mobilization of the limb was started from 3 to 5 days. Partial weight bearing was started after confirmation of commencement of healing process till fracture union. The Functional outcome was assessed using NEER score at final follow up. Total range of motion of knee joint was noted (Figure 3) at least 6 months after the surgery and patient's satisfaction based on surgical outcomes were assessed individually. Statistical analysis was done with SPSS version 16 using descriptive statistical methods including the Pearson Chi squared test and student-t test. A p value of $<0.05$ was considered as statistically significant.

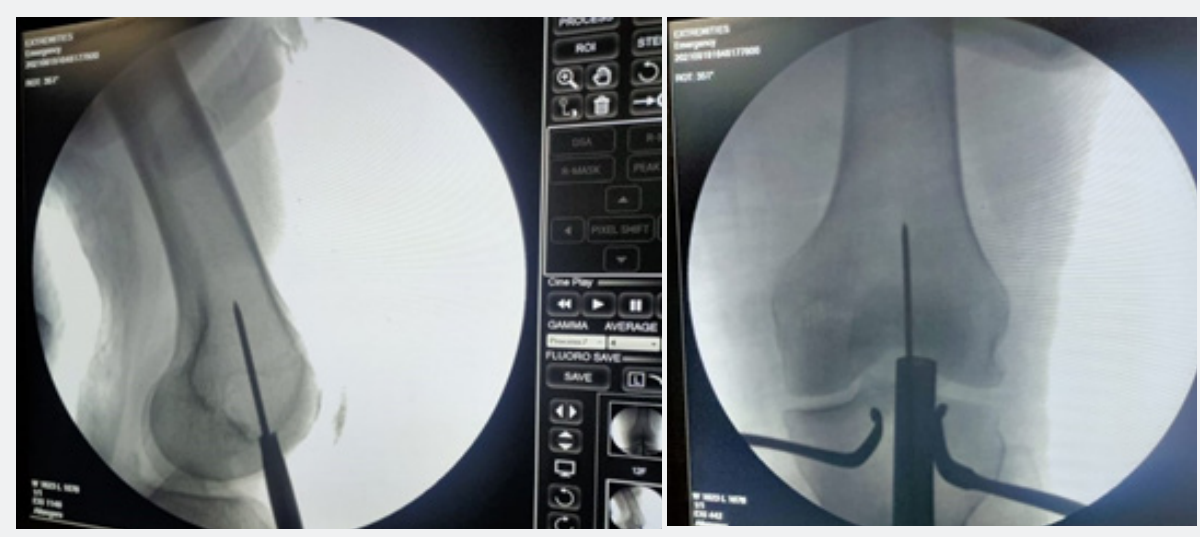

Figure 1: Guide Wire position in Lateral and AP view.
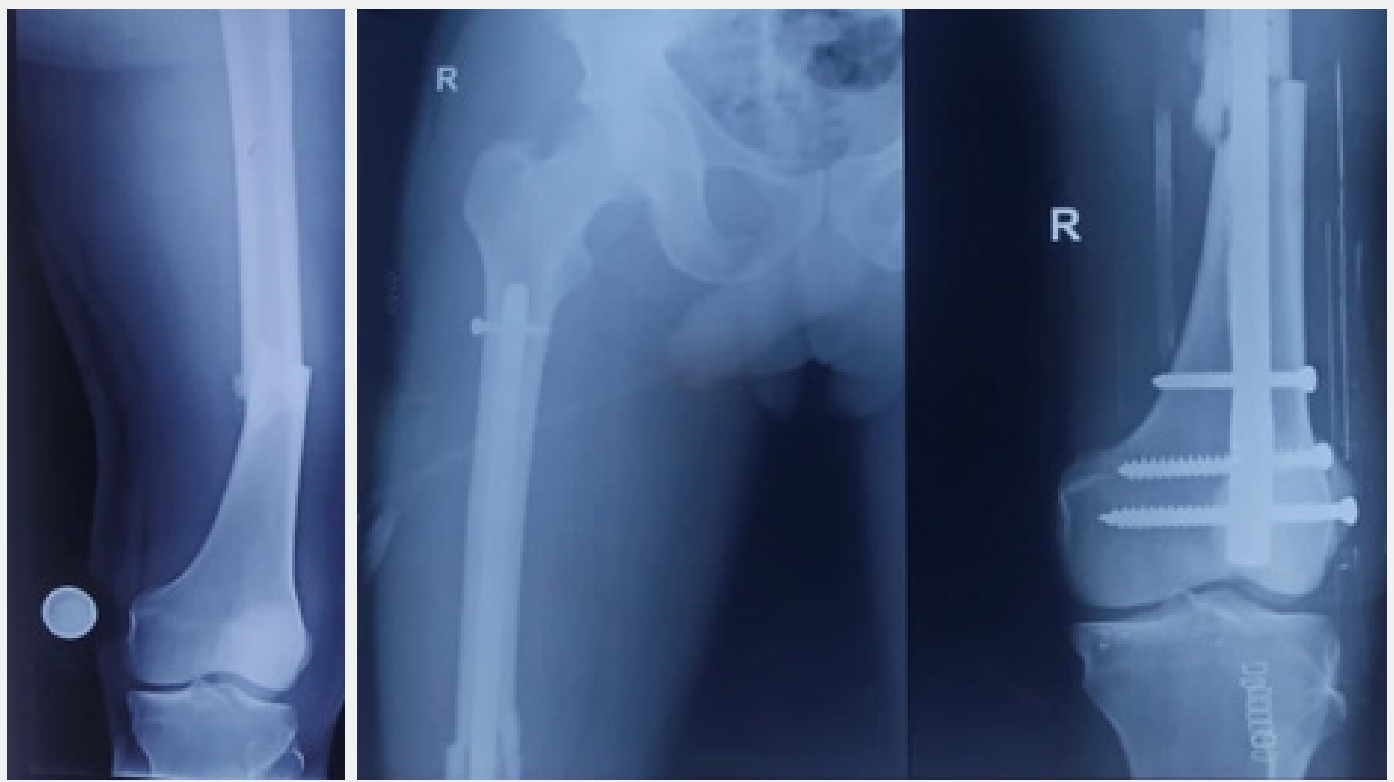

Figure 2: Preoperative X-ray and Postoperative X-ray. 


\section{Orthopedics and Rheumatology Open Access Journal (OROAJ)}
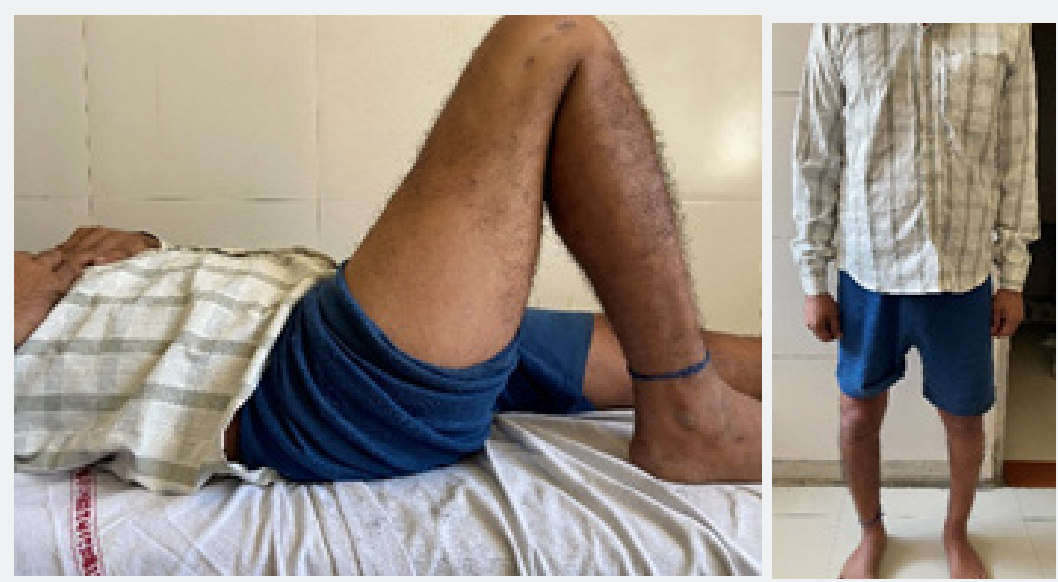

Figure 3: Showing range of motion of knee at final follow up.

\section{Results}

The mean age was $41.75 \pm 12.52$ with a range of $20-70$ years. There were 6 males (60\%) and 4 females (40\%). Right side was involved in 7 patients $(70 \%)$ while left side was involved in 3 patients (30\%). 9 patients (90\%) had Roadside accident (RSA) as mode of trauma for their fracture and 1 patient (10\%) had assault as the mechanism of injury for their fracture. Mean operating time was $125 \pm 10.15$ minutes. Mean blood loss was $230 \pm 20.5 \mathrm{ml}$. All the patients had closed fractures. Mean time for union was $16.15 \pm 1.35$ weeks (Table 1). 1 patient had decreased ROM due to stiffness at the knee joint due to poor compliance of physiotherapy exercises. 1 patient had superficial infection which was managed with intravenous antibiotics. No deep infection was noted. One case of non-union was noted in this study (Table 2). 1 patient had anterior knee pain. Range of motion at knee at final follow up was $125.25 \pm 17.34$ degrees. Results using NEER scoring system showed excellent outcome in 6 patients (60\%), good results in 2 patients (20\%), fair result in 1 patient $(10 \%)$ and poor result in 1 patient (10\%). The mean NEER score was $83.15 \pm 9.29$ with a range of 54-91.

Table 1: Showing demographic profile and results.

\begin{tabular}{|c|c|}
\hline Parameter & Number \\
\hline Mean Age & $41.75 \pm 12.52$ \\
\hline Sex & $\begin{array}{l}M=6 \\
F=4\end{array}$ \\
\hline Side & $\begin{array}{l}R=7 \\
L=3\end{array}$ \\
\hline Mode of Injury & $\begin{array}{c}\text { RSA-9 } \\
\text { Assault- } 1\end{array}$ \\
\hline Mean time of fracture healing (weeks) & $16.15 \pm 1.35$ \\
\hline Mean Range of Motion (degrees) & $125.25 \pm 17.34$ \\
\hline Mean operating time (minutes) & $125 \pm 10.15$ \\
\hline Mean blood loss (ml) & $230 \pm 20.5$ \\
\hline
\end{tabular}

Table 2: Complications.

\begin{tabular}{|c|c|}
\hline Complication & No of patients \\
\hline Superficial infection & 1 \\
\hline Deep infection & 0 \\
\hline Non union & 1 \\
\hline Knee stiffness & 1 \\
\hline Knee Pain & 1 \\
\hline
\end{tabular}

\section{Discussion}

Treatment of distal femoral fractures with a blade-plate has been associated with various complication.6 The common complications of pseudoarthrosis and fracture mal-alignment are associated with the eccentric plate positioning and periosteal stripping at the fracture site [7]. The iatrogenic soft tissue trauma and devascularization of the periosteum during the extramedullary implant fixation may increase the risk of infection and delayed union. To avoid some of the complications encountered with previous methods in the treatment of distal femoral fractures, several intramedullary implants have been developed in the past few years [8]. Intramedullary nailing has several advantages in that it is a load sharing device, thus giving good mechanical advantages and high union rate, reduced blood loss and infection risk, reduced operative time and decreased hospital stay leading to better functional outcomes [9]. Retrograde nailing can achieve a relatively longer working length, and more interlocking screws can be applied in the distal segment providing better stability of the fracture. Despite damage to the articular cartilage and postoperative knee pain, retrograde nailing is known to offer advantage over antegrade nailing for below isthmus femoral shaft fractures in terms of implant insertion, control of the short distal segment and fixation strength $[10,11]$. Supine positioning during retrograde nailing allows greater control of the axis as well as fluoroscopic control of the greater trochanter during the surgery. In obese patients or patients with multiple fractures, retrograde nailing is technically easier, allows easier access to other fractures, and obviates the need for traction table [12]. 
We achieved $90 \%$ union rate in our study which was comparable to Herscovici et al. [13] who reported 96\% union rate with retrograde nailing in their series. So, the retrograde nailing shows excellent union rate. There is a risk of knee sepsis with trans articular nailing procedure compared to plating, thus we recommend the use of meticulous antibiotic prophylaxis after the surgery. There was no case of knee sepsis noted in our series. Mean time for fracture union was $16.15 \pm 1.35$ weeks which corroborates with results of Handolin et al. [14] (mean union time of the fracture was 17.5 weeks) [2]. Mean blood loss in our study $(230 \pm 20.5 \mathrm{ml})$ was comparable to Ricci et al $(250 \mathrm{ml})$ [15]. Knee pain is one of the most common complications described after retrograde intramedullary nailing. It has been reported as high as $70 \%$ in one of the studies done by Acharya et al. [16] Herscovici et al. [17] reported results of forty-five femoral shaft fractures treated with retrograde unreamed intramedullary femoral nailing. Forty-three fractures healed in their study (96 percent). They concluded that retrograde distal femoral nailing is an effective method for femoral fracture management. In our study, anterior knee pain was seen in $10 \%$ of patients which was less than that reported by Shah et al in their study (23\%) [5]. Injury to the knee is common in femoral shaft fractures, and that could be one of the causes of knee pain. The surgical technique and position of distal screws could be responsible for knee pain. One possible factor, which may cause future deficiencies in the knee joint, is bone debris generated during reaming and nail insertion. We feel that it is important to perform a thorough knee joint lavage before final wound closure. The limitation of this study is small no of cases and short follow up. The long-term effects and complications of retrograde femoral intramedullary nailing on knee joint function are yet to be identified.

\section{Conclusion}

We achieved satisfactory results using a distal femoral nail in the management of patients with distal femoral fracture. Early mobilisation and low risk of fracture healing complications are seen with distal femoral nailing. In femoral shaft fractures retrograde nailing offer a valuable alternative.

\section{References}

1. Walcher F, Frank J, Marzi I (2000) Retrograde nailing of distal femoral fracture-_clear and potential indications. Eur J Trauma 4: 155-168.
2. Handolin L, Pajarinen J, Lindahl J, Hirvensalo E (2004) Retrograde intramedullary nailing in distal femoral fractures--results in a series of 46 consecutive operations. Injury 35(5): 517-522.

3. Muller M, Allgower M, Schneider R (1991) Manual of internal fixation. Berlin-Heidelberg, Springer, New York, USA.

4. Scheerlink T, Krallis P, Descamps P, Delince H (1998) The femoral supracondylar nail: preliminary experience. Acta Orthop Belg 64(4): 385-391.

5. Shah S, Desai P, Mounasamy V (2015) Retrograde nailing of femoral fractures: a retrospective study. Eur J Orthop Surg Traumatol 25(6): 1093-1097.

6. Ito K, Hungerbuhler R, Wahl D, Grass R (2001) Improved intramedullary nail interlocking in osteoporotic bone. J Orthop Trauma 3: 192-196.

7. Seifert J, Stengel D, Matthes G, Hinz P, Ekkernkamp A, et al. (2003) Retrograde fixation of distal femoral fractures: results using a new nail system. J Orthop Trauma 17(7): 488-495.

8. El-Kawy S, Ansara S, Moftah A,Shalaby H, Varughese V (2007) Retrograde femoral nailing in elderly patients with supracondylar fracture femur; is it the answer for a clinical problem? Int Orthop 31(1): 83-86.

9. Garnavos C, Lygdas P, Lasanianos NG (2012) Retrograde nailing and compression bolts in the treatment of type $\mathrm{C}$ distal femoral fractures. Injury 43(7): 1170-1175.

10. Giddie J, Sawalha S, Parker M (2015) Retrograde nailing for distal femur fractures in the elderly. SICOT J 1: 31.

11. Neubauer T, Ritter E, Potschka T, Karlbauer A, Wagner M (2008) Retrograde nailing of femoral fractures. Acta Chir Orthop Traumatol Cech 75(3): 158-166.

12. Kim JW, Oh CW, Oh JK, Park KH, Kim HJ, et al. (2018) Treatment of infraisthmal femoral fracture with an intramedullary nail: Is retrograde nailing a better option than antegrade nailing? Arch Orthop Trauma Surg 138(9): 1241-1247.

13. Herscovici D Jr, Whiteman KW (1996) Retrograde nailing of the femur using an intercondylar approach. Clin Orthop Relat Res 332: 98-104.

14. Leggon RE, Feldmann DD (2001) Retrograde femoral nailing: a focus on the knee. Am J Knee Surg 14(2): 109-118.

15. Ricci WM, Bellabarba C, Evanoff B, Herscovici D, DiPasquale T, Sanders R (2001) Retrograde versus antegrade nailing of femoral shaft fractures. J Orthop Trauma 15(3): 161-169.

16. Acharya K, Rao M (2006) Retrograde nailing for distal third femoral shaft fractures: a prospective study. J Orthop Surg 14(3): 253-258.

17. Herscovici D Jr, Whiteman KW (1996) Retrograde nailing of the femur using an intercondylar approach. Clin Orthop 332: 98-104. 

(C) Commons Attribution 4.0 License

DOI: 10.19080/OROAJ.2021.19.556009

\section{Your next submission with Juniper Publishers} will reach you the below assets

- Quality Editorial service

- Swift Peer Review

- Reprints availability

- E-prints Service

- Manuscript Podcast for convenient understanding

- Global attainment for your research

- Manuscript accessibility in different formats ( Pdf, E-pub, Full Text, Audio)

- Unceasing customer service

Track the below URL for one-step submission https://juniperpublishers.com/online-submission.php 